\title{
Iron and phosphorus deprivation induce sociality in the marine bloom-forming cyanobacterium Trichodesmium
}

\author{
Yael Tzubari ${ }^{1} \cdot$ Liel Magnezi $^{1} \cdot$ Avraham Be'er $^{2} \cdot$ Ilana Berman-Frank $^{1}$
}

Received: 31 August 2017 / Revised: 23 January 2018 / Accepted: 25 January 2018 / Published online: 20 February 2018

(c) International Society for Microbial Ecology 2018

\begin{abstract}
Trichodesmium spp. are diazotrophic cyanobacteria that exist as single filaments (trichomes) and as macroscopic colonies of varying shapes formed by aggregating trichomes. The causes and dynamics of colony formation and disassociation are not yet elucidated. we demonstrate that limited availability of dissolved phosphorus $(\mathrm{P})$ or iron $(\mathrm{Fe})$ stimulated trichome mobility and induced colony formation in Trichodesmium erythraeum IMS101 cultures. The specific nutrient limitation differentially affected the rate of colony formation and morphology of the colonies. Fe starvation promoted rapid colony formation (10-48 h from depletion) while 5-7 days were required for colonies to form in P-depleted cultures. Video analyses confirmed that the probability of trichomes to cluster increased from 12 to $35 \%$ when transferred from nutrient replete to Fedepleted conditions. Moreover, the probability for Fe-depleted aggregates to remain colonial increased to 50\% from only $10 \%$ in nutrient replete cultures. These colonies were also characterized by stronger attachment forces between the trichomes. Enrichment of nutrient-depleted cultures with the limited nutrient-stimulated colony dissociation into single trichomes. We postulate that limited $\mathrm{P}$ and $\mathrm{Fe}$ availability enhance colony formation of Trichodesmium and primarily control the abundance and distribution of its different morphologies in the nutrient-limited surface ocean.
\end{abstract}

\section{Introduction}

The filamentous $\mathrm{N}_{2}$-fixing marine cyanobacterium Trichodesmium spp., known for its extensive oceanic blooms across the nutrient-poor (oligotrophic) subtropical and tropical ocean, exists as both single filaments (trichomes) and as colonies comprised of aggregated trichomes (averaging around $\sim 50$ to 200 trichomes per colony) [1]. Colonies can be spherical or fusiform and are termed "puffs" or "tufts" (sometimes "rafts"), respectively [2]. Colony morphology

These authors contributed equally: Yael Tzubari, Liel Magnezi.

Electronic supplementary material The online version of this article (https://doi.org/10.1038/s41396-018-0073-5) contains supplementary material, which is available to authorized users.

$\triangle$ Ilana Berman-Frank

ilana.berman-frank@biu.ac.il

1 Mina and Everard Goodman Faculty of Life Sciences, Bar Ilan University, Ramat Gan 529002, Israel

2 Zuckerberg Institute for Water Research, The Jacob Blaustein Institutes for Desert Research, Ben-Gurion University of the Negev, Sede Boqer Campus 84990, Midreshet Ben-Gurion, Israel does not depend on the Trichodesmium clade or species with both forms reported for these taxonomic classifications [3] and with individual colonies comprised at times of multiple species $[4,5]$.

Trichodesmium's capacity for fixing atmospheric dinitrogen (diazotrophy) overcomes the scarcity of fixed inorganic nitrogen $(\mathrm{N})$ in the oligotrophic surface oceans it inhabits [6]. Since Trichodesmium was first characterized as a cyanobacterial diazotroph [7], its colonial morphologies have been attributed with several metabolic and evolutionary advantages. Early hypotheses that colonial morphologies in Trichodesmium are required for $\mathrm{N}_{2}$ fixation [8] have been replaced by data demonstrating that both free trichomes and colonies fix $\mathrm{N}_{2}$ [9] and that free trichomes can optimize $\mathrm{N}_{2}$ fixation by a combined spatial and temporal separation of the incompatible processes of photosynthesis and $\mathrm{N}_{2}$ fixation [10].

Studies on colonies have indicated that these morphologies are advantageous in providing oxygen-reduced zones in the colony center promoting higher $\mathrm{N}_{2}$ fixation rates [11]; increasing vertical migration [12-14]; enabling "nutrient mining" from depth [13, 15, 16]; enhancing the process of taking-up, storing, and dissolving iron oxides and eolian dust [17, 18]; and facilitating nutrient 
supply and acquisition via the resident holobiont/epibiont communities [19].

Cultures of Trichodesmium characteristically produce colonies during the stationary growth phases when nutrients may be depleted [20-22] and when $\mathrm{pH}$ increases substantially at high biomass or under high oxygen stress [23]. Increasing colony abundance was also correlated with higher salinities and temperatures in a transect across the Atlantic [24]. Yet, the exact environmental or biotic parameters inducing trichome aggregation and colony formation in Trichodesmium have yet to be determined.

Bioavailable iron $(\mathrm{Fe})$ and phosphorus $(\mathrm{P})$ are critical parameters regulating Trichodesmium distribution worldwide [18, 25-27]. In this study, we thus examined the hypothesis that nutrient limitation, specifically limited availability of Fe and P, drives motility, colony formation, and the subsequent characteristics of the colonies formed.

\section{Methods}

\section{Cultures and experimental setups}

For all experiments, we used non-axenic cultures of Trichodesmium erythraeum IMS101, where Trichodesmium dominated the biomass and associated epibionts were found in very low copy numbers during the experiments (see Supplementary Table S1). To reduce variations in cellular responses due to culture age, all experiments were performed on exponentially growing cultures that were gravity filtered onto polycarbonate filters $(10 \mu \mathrm{m}$ pore size $)$ and washed with $3 \times 50 \mathrm{ml}$ of the required media (Fe-depleted or P-depleted or full YBCII) to remove the old media and unassimilated nutrients. The resuspended cultures were incubated in polycarbonate Nalgene bottles filled with autoclaved YBCII medium [20] that was utilized as either replete (full medium), P-depleted $\left(-\mathrm{PO}_{4}\right)$ to which no phosphorus was added, or Fe-depleted (-Fe) with no $\mathrm{Fe}$ added. Cultures were maintained at $25^{\circ} \mathrm{C}$ under a 12:12 light:dark cycle and white fluorescent light intensity of 80-100 $\mu$ mol quanta $\mathrm{m}^{-2} \mathrm{~s}^{-1}$ with no external bubbling with air. Nutrient-depleted media was prepared in $10 \mathrm{~L}$ polycarbonate Nalgene bottles washed with acid $(10 \% \mathrm{HCl})$ and rinsed three times with ultra-distilled water. Fe-depleted cultures were not tested for dissolved $\mathrm{Fe}$ as no $\mathrm{Fe}$ was added. Moreover, identically grown cultures showed increasing expression of the diagnostic prokaryotic iron stress-response gene $i s i B$ [28] for $48 \mathrm{~h}$ after Fe depletion from the medium [29]. To examine whether nutrient enrichment will impact the colonies formed, we added (Rescue treatment) Fe-EDTA or $\mathrm{KH}_{2} \mathrm{PO}_{4}$ to the corresponding depleted culture $24 \mathrm{~h}(\mathrm{~h})$ or 5 days after depletion at a concentration matching $\mathrm{Fe}$ and $\mathrm{P}$ concentrations of replete YBCII at $T_{0}$.

\section{Colony formation}

To examine whether colony formation required live trichomes, we divided a replete $T$. erythraeum IMS101 culture to four subcultures that were subsequently transferred to Fedepleted media, retained as untreated (controls), or immediately killed by one of three different and independent treatments chosen to maintain trichome morphology as in live cultures: UV radiation, microwaving, or by fixation with $1.5 \%$ glutaraldehyde. After treatment, the subcultures were examined for $24 \mathrm{~h}$ to observe trichome motility and quantify colony numbers (after $24 \mathrm{~h}$ ).

\section{Influence of the initial culture density on colony formation}

To quantify the effect of initial culture density on the number of colonies formed, we divided a replete and exponentially growing $T$. erythraeum IMS101 culture into five subcultures each with a different cellular concentration (from 1000 cells $\mathrm{ml}^{-1}$ to 160,000 cells $\mathrm{ml}^{-1}$ ). The subcultures were then transferred (after appropriate washing in depleted media) to bottles containing $\mathrm{Fe}$ - and P-depleted media and the number of colonies formed for each subculture were counted daily. Data presented here are from colonies formed at day 2 (after $48 \mathrm{~h}$ ) in the Fe-depleted cultures and from day 6 in the P-depleted cultures as our preliminary experiments demonstrated this was the time required for the colonies to appear at each of the specific depletions. These experiments were repeated independently three times with three different stock cultures.

\section{Live imaging of cells and colonies}

To track trichome movement and colony formation, cultures were placed within a $35 \mathrm{~mm}$ TC Treated Glass Bottom CELLview cell culture dish (Greiner Bio-One $\mathrm{GmbH}$, Kremsmünster, Austria) directly prior to imaging. Real-time imaging was performed using a M205 FA Fluorescence Stereo Microscope (Leica Microsystems GmbH, Wetzlar, Germany) for $10 \mathrm{~h}$ with images taken every $30 \mathrm{~s}$.

\section{Quantification and characterization of trichome movement}

Quantification and characterization of trichome movement. We used an Axio Imager Z2 optical microscope (Zeiss), equipped with a GX1050 video camera (Allied Vision 
Technologies) and Matlab software programmed to detect the motion of the trichomes and store their coordinates at any single frame, obtaining a smooth trajectory. The software detects trichomes and stores their center of mass in the memory. Trichomes were moving in all directions; if two trichomes collided, and remained together for more than $30 \mathrm{~s}$, we considered them attached. We then calculated the fraction of attached trichomes from the total of trichomes that collided with each other. We also examined the probability for the attached trichomes to remain together (coalesce) for a time period of minutes to hours.

\section{Cell and colony counts}

T. erythraeum IMS101 live cells and colonies were counted in a S50 Sedgwick-Rafter Cell (Pyser-SGI ltd., Edenbridge, UK) using an Eclipse 80i microscope equipped with a DXM 1200F camera (Nikon, Tokyo, Japan). Trichome (free and within colonies) and colony numbers and sizes were measured using $\times 40$ magnification. Cell lengths were measured at $\times 400$ magnification. Image analyses were performed using ImageJ (NIH, Bethesda, MD, USA). For the experiments presented in Table 1, samples were fixed with $1.5 \%$ glutaraldehyde final concentration and flash frozen in liquid nitrogen. The preserved trichomes were measured and enumerated using a Cytosub flow cytometer (Cytobuoy, Woerden, the Netherlands). As we were interested in the colonies as a unit, the number of colonies were normalized to the total number of cells (sum of cells in free trichomes + cells in colonies). In this study on Trichodesmium IMS101 cultures, we did not distinguish between tufts or puffs and refer to both morphological forms as colonies. Growth rates $(\mu)$ were calculated according to the following equation: $\mu\left(d^{-1}\right)=\left(\ln \quad\left(\mathrm{N}_{1}\right)-\ln \left(\mathrm{N}_{0}\right)\right) / T_{1}-T_{0}$, where $\mathrm{N}_{0}$ and $\mathrm{N}_{1}$ are cell concentrations at the beginning $\left(T_{0}\right)$ and the end $\left(T_{1}\right)$ of sampling, and $T_{1}-T_{0}$ is the time period (in days) between sampling.

Table 1 Influence of $\mathrm{Fe}$ availability on colony formation in exponentially growing $T$. erythraeum IMS101 in replete YBCII media

\begin{tabular}{lll}
\hline Fe concentration $(\mathrm{nM})$ & $\begin{array}{l}\text { Colony number per } \\
\text { total cell numbers }\end{array}$ & $\begin{array}{l}\text { Trichome length } \\
(\mathrm{mm})\end{array}$ \\
\hline 0 & $37.9 \pm 5.0$ & $0.2 \pm 0.1$ \\
4 & $42.4 \pm 22.3$ & $0.3 \pm 0.2$ \\
40 & $1.0 \pm 1.0$ & $0.3 \pm 0.2$ \\
400 & $4.9 \pm 2.7$ & $0.4 \pm 0.2$ \\
\hline
\end{tabular}

Cultures were subsequently transferred to YBCII media with adjusted Fe-EDTA concentrations. Averages of total cell numbers (cells ml ${ }^{-1}$ ), trichome length, and colony number (colony number per total cell number) \pm SD were determined after 3 days. $n=3$ for all treatments

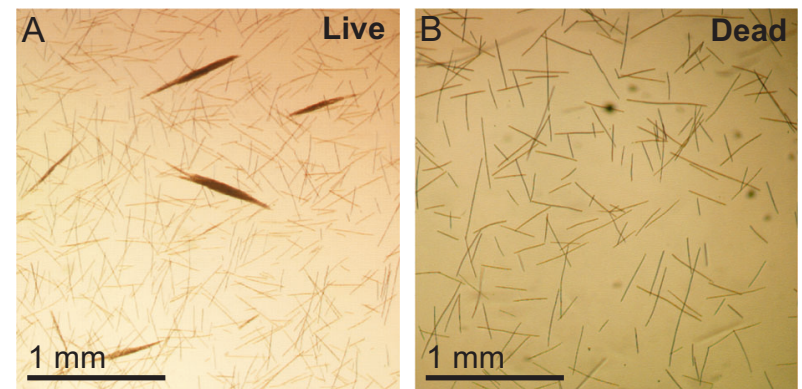

Fig. 1 Colony formation in T. erythraeum IMS101 laboratory cultures as observed $24 \mathrm{~h}$ after exponentially growing cultures were washed and resuspended in Fe-depleted media (a) while no colonies formed in a subculture that was fixed with glutaraldehyde after resuspension in Fe-depleted media (b). Images represent one of five replicate experiments

\section{Scanning electron microscopy}

We used the GTGO protocol [30] to prepare the samples for imaging. T. erythraeum IMS101 colonies were pre-fixed in $1.5 \%$ glutaraldehyde, washed with Dulbecco's phosphate buffered saline (DPBS) without $\mathrm{Mg}^{+3}$ and $\mathrm{Ca}^{+3}$ (Biological Industries Israel Beit Haemek Ltd. ISRAEL) to remove excessive fixative. The colonies were then post-fixed in $4 \%$ osmium tetraoxide for $60 \mathrm{~min}$ and washed again with the DPBS buffer. The colonies were dehydrated gradually by $10 \mathrm{~min}$ incubations in increasing concentrations of ethanol (50, 70, 80, 90, and 100\% ethanol). Dehydrated samples were air dried and subsequently coated with gold or carbon. Images were taken with the Quanta FEG Environmental Scanning Electron microscope-ESEM (FEI, Company, Hillsboro, OR, USA).

\section{Statistics}

Colony formation in nutrient-depleted media was compared to replete controls using an ANOVA repeated measure linear model. The number of colonies formed per initial cell density under Fe depletion were compared to the P-depleted or Fe-depleted colonies using a univariate analysis of variance (testing between-subject effects). Comparisons of colony and trichome lengths in Fe-depleted, P-depleted, and replete media were performed using a two-tailed $t$-test.

\section{Results}

\section{Live motile trichomes are required to form colonies}

A priori, if colony formation is a biological response, the formation of colonies would require living cells and will not result from physical surface interactions of the medium 

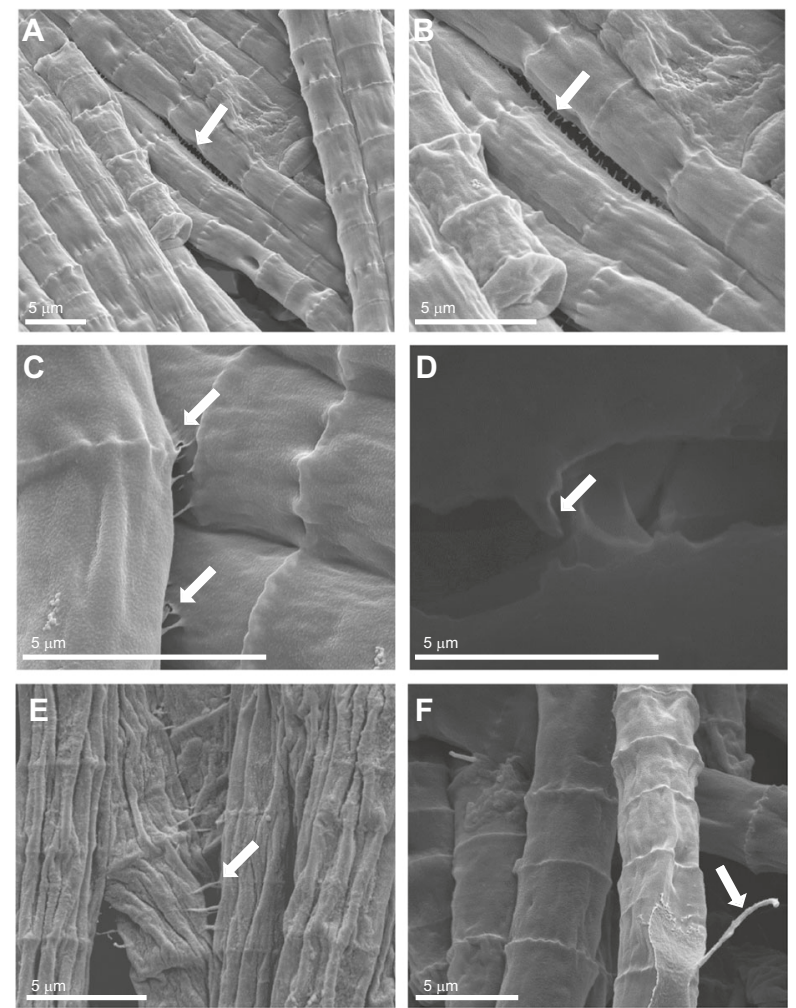

Fig. 2 Scanning electron microscopy (SEM) images of colonies and trichomes from stationary phase Trichodesmium erythraeum IMS101 grown in replete YBCII media (a-d, f) and after 2 days in Fe-depleted media (e). Images highlight appendages (marked by arrows) that connect between the lengths of trichomes $(\mathbf{a}-\mathbf{b})$; from cell border to adjacent cell border (c-d); and bridging between adjacent trichomes (e). Also, observed were hair-like protrusions (f) that may attach trichomes to one another or aid in mobility. Colonies and trichomes were coated with gold or carbon (d was air-dried and carbon coated) and analyzed with an environmental scanning electron microscope (Quanta FEG SEM). Scale bars and magnifications are noted at the bottom of each image

causing aggregations. Colony formation occurred after $24 \mathrm{~h}$ only in the live cultures (all samples were under Fe starvation) (Fig. 1a). Killing the cultures immediately after cultures were transferred to Fe-depleted media by three different treatments, aimed to maintain the integrity of the trichomes (treatment with UV, glutaraldehyde, and microwave), resulted in the complete absence of aggregation or colony formation (Fig. 1b). When colonies formed, we observed that trichomes attached to each other with cellular appendages (Fig. 2a, b, c) forming bridges between two trichomes (Fig. 2d, e). Colonies also displayed different adhesive properties than single trichomes as measured using an atomic force microscope (AFM) (Supplementary Figure S1) with the generated adhesion maps showing fourfold higher adhesive forces in colonial trichomes compared to single trichomes from the same cultures and conditions (18 $\mathrm{nN}$ and $4 \mathrm{nN}$, respectively) $(n=86, p<0.001)$. We also observed longer hair-like structures $(\sim 5-7 \mu \mathrm{m}$ length)
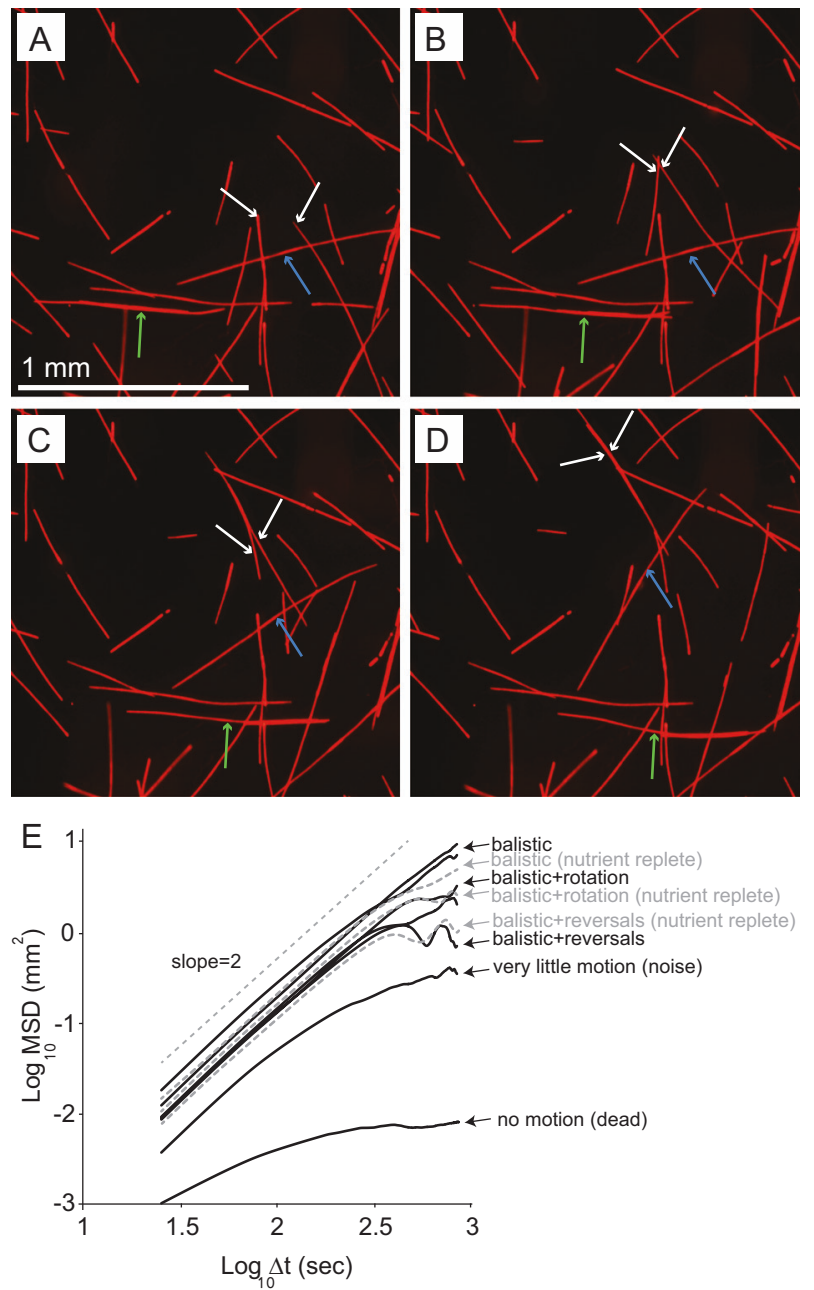

Fig. 3 Motility patterns of T. erythraeum IMS101 trichomes obtained from sequential images (a-d) of Fe-depleted cultures showing different types of trichome movement (full video in supplementary). White arrows indicate a forward ballistic movement with trichomes merging with each other; blue arrows indicate rotating movement, and the green arrows show forward movement that occurs while trichome is attached and "gliding" on adjacent trichomes. Also, note that one of the trichomes (the shorter) is moving faster by "riding" on the longer trichome. (e) Motility patterns for dead, nutrient-replete, and Fe-depleted cultures as represented by the mean square displacements (MSD) of trichomes as a function of time (log-log scale) showing no difference between the nutrient-replete and deplete trichomes

(Fig. 2f) that may play a role in attachment of trichomes to one another.

The movement of single trichomes to form colonies was characterized by tracking the motion of each trichome along its main axis (directed parallel to its body), and following trichome rotations about the axes located (randomly) at any point on their body. Trichome motion was ballistic (motion in straight lines and constant speed, then possibly merging with other trichomes) and rotational-with trichomes twisting and turning (Fig. 3a, b, c, d and Supplementary Videos 1-3). Trichomes also used other trichomes to facilitate movement (possibly by gliding) with the relative 
motion of one trichome different with respect to the adjacent trichome (Supplementary Figure S2 and Supplementary Video 4). Trichome motion was composed of ballistic regimes with reversals and rotations; observed when plotting the mean square displacements (MSD) of the single trichomes as a function of time (Fig. 3e). Trichomes came together, remained attached, and disaggregated within a timescale from tens of seconds to several hours (Supplementary Videos 2-3). This characteristic motion was only observed in live cultures and not in dead ones and was independent of nutrient status (Fig. 3e). The typical trichome speed was $\sim 2 \mu \mathrm{m} \mathrm{s}^{-1}$ corresponding to $\sim 50$ bodylengths per hour.

\section{Iron and phosphorus limitation induce colony formation and influence colony morphology}

Colonies formed when exponentially growing cultures were resuspended in $\mathrm{Fe}$ - or P-depleted media and incubated under otherwise regular growth conditions. Although the cultures were treated similarly (i.e., in Fe- or P-free medium), the response time of the cultures regarding colony formation differed in all of our experiments with $\mathrm{Fe}$ depletion causing colonies to appear 24-48 $\mathrm{h}$ after depletion while colonies in P-depleted cultures formed only after 5-7 days. Thus, counts from $48 \mathrm{~h}$ (Fe-depleted) and 6 days (P-depleted) clearly show that the initial culture density influenced the rate and the number of colonies formed (Fig. 4). Under Fe-depleted conditions, linear regression

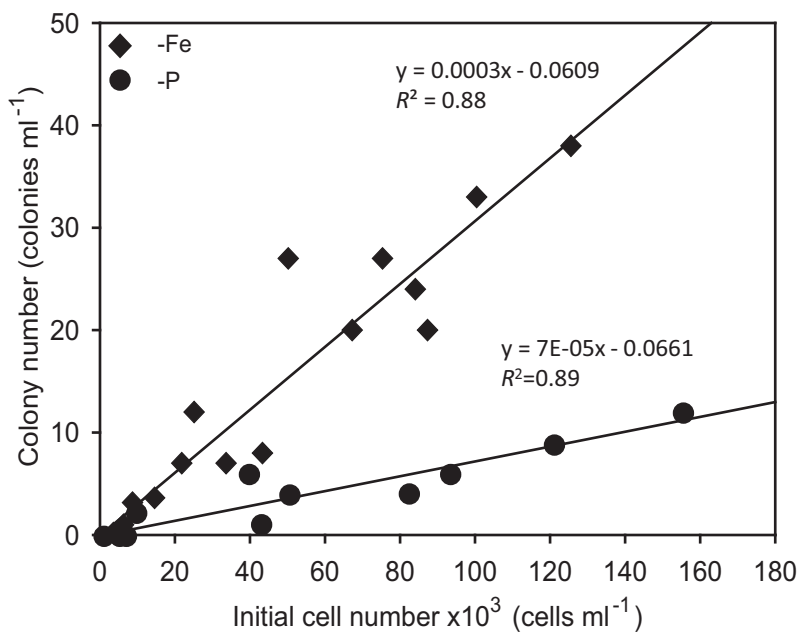

Fig. 4 Linear regressions of the initial culture density vs. the number of colonies formed in T. erythraeum IMS101 cultures 2 days after resuspension of different cell densities in Fe-depleted media (black diamonds) $\left(R^{2}=0.88, n=15, p<0.001\right)$ and 6 days after resuspension in P-depleted cultures (black circles) $\left(R^{2}=0.89, n=15, p<\right.$ 0.001). The difference in the day when colonies were quantified for each specific treatment was due to the varied response time required for colonies to appear under $\mathrm{P}$ or Fe depletion analysis revealed that the minimum number of cells required for colony formation was 230 cells $\mathrm{ml}^{-1}$ $\left(R^{2}=0.88, n=15, p<0.001\right)$ while in P-depleted media the minimum number of cells required to form colonies was fourfold higher, 944 cells $\mathrm{ml}^{-1}\left(R^{2}=0.89, \quad n=15\right.$, $p<0.001)$. Moreover, under $\mathrm{Fe}$ depletion, the number of colonies formed, prior to the demise (or biomass crash) of the culture, was significantly higher than the number of colonies formed under $\mathrm{P}$ limitation $(p<0.001, n=15)$ (Fig. 4).

\section{Fe depletion}

Upon transfer of exponentially growing cultures to the $\mathrm{Fe}$ depleted media, cell numbers of the culture declined rapidly (mortality rate -0.4 per day within 2 days) compared to the control culture where transfer to a new medium produces a lag phase prior to exponential growth $(\mu=0.2$ per day $)$ (Fig. 5a). As the biomass of Fe-depleted cultures declined, the number of colonies formed after $24 \mathrm{~h}$ was fivefold higher than in the replete media $\left(7.5 \times 10^{-5}\right.$ colonies per cell vs. $1.4 \times 10^{-5}$ colonies per cell, respectively) (Fig. $5 \mathrm{c}$ ). This difference increased to sevenfold after $48 \mathrm{~h}(p<0.01$, $n=3$ ), when the Fe-depleted media contained $16 \times 10^{-5}$ colonies per cell while the replete media contained $2.3 \times 10$ ${ }^{-5}$ colonies per cell. Yet, within 3 days of Fe depletion, both colonies and single trichomes began to disintegrate and the numbers of both morphologies declined drastically (Fig. 5a, c).

Varying Fe concentrations (rather than just depleting the media from $\mathrm{Fe}$ ) also impacted colony formation and trichome length (Table 1). In another experiment, cultures transferred to Fe-depleted and low $(4 \mathrm{nM}) \mathrm{Fe}$ had, 3 days after depletion, $37.9 \times 10^{-5}$ and $42.4 \times 10^{-5}$ colonies per cell, respectively; significantly more colonies than in cultures transferred to $40 \mathrm{nM}$ and $400 \mathrm{nM}$ Fe with $1.0 \times 10^{-5}$ and $4.9 \times 10^{-5}$ colonies per cell, respectively $(p<0.04$, $n=3$ ). Cultures under lower $\mathrm{Fe}$ concentrations also had shorter trichomes than the $400 \mathrm{nM} \mathrm{Fe}$ media control $(p<0.001, n=64)$.

\section{$\mathrm{P}$ depletion}

When exponentially growing cultures were transferred to a P-depleted medium, a similar process resulted, although the response of the cultures to $\mathrm{P}$ depletion was significantly slower than for cultures stressed by $\mathrm{Fe}$ limitation, with colonies forming 5-7 days after induction (Fig. 5d). Difference in growth rates was minor between the P-replete (0.2 per day) and P-depleted ( 0.13 per day) cultures for $\sim 8$ days after induction (Fig. 5b). Yet, alkaline phosphatase activity (APA), that increases in Trichodesmium when bioavailable $\mathrm{P}$ is limited [31], significantly differed between 
Depletion (A-D)
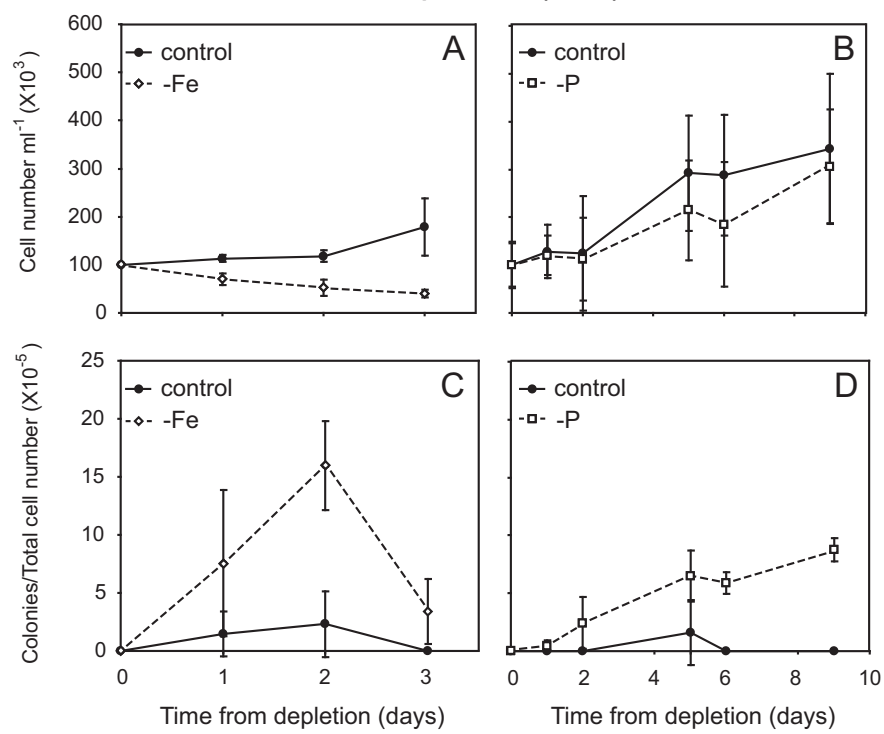

Fig. 5 Daily changes in total cell concentrations (a, b) and colony numbers normalized to total cell numbers $(\mathbf{c}, \mathbf{d})$ of exponentially growing nutrient replete (filled circles) T. erythraeum IMS101 cultures that were transferred to either Fe-depleted (empty diamond) or Pdepleted (empty squares) media (a-d). Daily changes in total cell concentrations $(\mathbf{e}, \mathbf{f})$ and colony numbers normalized to total cell numbers $(\mathbf{g}, \mathbf{h})$ after nutrient enrichment (rescue treatment) of Fe-

the two treatments. The alkaline phosphatase turnover time decreased 16-fold in P-depleted cultures compared to a 3fold reduction in the replete cultures during the same time; from $93.3 \mathrm{~h}$ on day 0 to $5.8 \mathrm{~h}$ on day 6 for the P-depleted cultures while in replete media cultures the alkaline phosphatase turnover times decreased from $104 \mathrm{~h}$ on day 0-34.5 $\mathrm{h}$ on day 6 (Supplementary Table S2). Accordingly, in the P-depleted cultures, the number of colonies per total number of cells was significantly higher $(p<0.008, n=3)$ than those formed in the replete media during the experiment (Fig. 5d). although the total number of colonies was lower than in corresponding Fe-depleted cultures (Fig. 5c). Five days after $\mathrm{P}$ depletion, we measured a four fold difference between treatments with $6.5 \times 10^{-5}$ colonies per cell and $1.6 \times 10^{-5}$ colonies per cell for the P-depleted and P-replete, respectively (Fig. 5d). On day 9, no colonies were observed in the P-replete media while in the P-depleted media colony abundance increased to $8.7 \times 10^{-5}$ colonies per cell (Fig. 5d).

The specific nutrient deprivation also impacted colony morphologies. The average length of Fe-depleted trichomes was $0.32 \mathrm{~mm}$, significantly shorter $(n=173, p<0.01)$ than trichomes from both P-depleted and replete media $(0.50 \mathrm{~mm}$ and $0.45 \mathrm{~mm}$, respectively) (Table 2). These shorter $\mathrm{Fe}$ stressed trichomes formed smaller colonies (average length $0.52 \mathrm{~mm}, n=73, p<0.01)$ than P-depleted colonies with an average length of $1.25 \mathrm{~mm}$ (Table 2). Accordingly, and
Enrichment $(\mathrm{E}-\mathrm{H})$
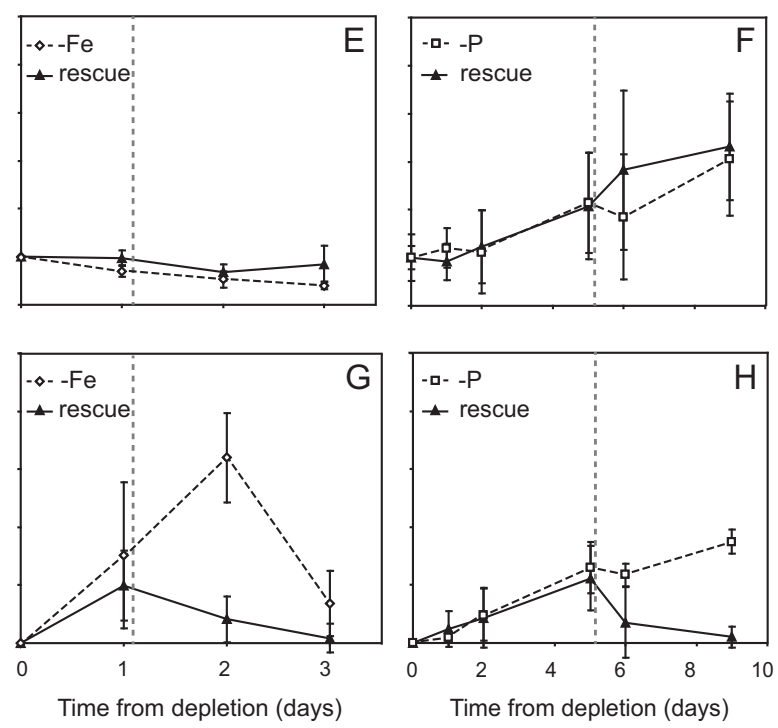

EDTA $(\mathbf{e}, \mathbf{g})$ or $\mathrm{KH}_{2} \mathrm{PO}_{4}(\mathbf{f}, \mathbf{h})$ to the corresponding depleted culture that was added $24 \mathrm{~h}$ or 5 days (symbolized by vertical gray line) after depletion at a concentration matching $\mathrm{Fe}$ and $\mathrm{P}$ concentrations of replete YBCII. Time scale of experiments differ in the Fe-depleted vs. P-depleted cultures due to the different rates of response to the stress imposed by the limiting nutrient ( $n=3$ independent biological stockcultures per treatment)

taking into account the different times and magnitude of response to the specific nutrient depletion, the average colony volume for Fe-depleted colonies was $\sim 50$-fold smaller at $1.2 \times 10^{-3} \mathrm{~mm}^{3}$ compared with $5.8 \times 10^{-4} \mathrm{~mm}^{3}$ for P-depleted cultures (Table 2).

\section{Iron and phosphorus enrichments stimulate colony dissociation}

Enrichment with Fe (rescue) of a Fe-depleted culture caused a $\sim 50 \%$ reduction in colony numbers after 1 day, from $4.9 \times 10^{-5}$ colonies per cell at the time of Fe enrichment to $2 \times 10^{-5}$ colonies per cell (Fig. $5 \mathrm{~g}$ ). During the same time frame, the abundance of colonies in the Fe-depleted media increased significantly by another $\sim 50 \%$, from $7.5 \times 10^{-5}$ colonies per cell to $16 \times 10^{-5}$ colonies per cell $(p<0.001$, $n=3)$.

Phosphate enrichment of a P-depleted media also prompted a reduction in colony numbers with the dissociation of existing colonies. During the first 5 days (post P-depletion and pre $\mathrm{PO}_{4}$ rescue), colonies were detected in all treatments (Fig. 5h). After the addition of phosphate to the rescue media, the number of colonies in the $\mathrm{PO}_{4}$ rescue media declined to $1.7 \times 10^{-5}$ colonies per cell on day $6(1$ day after rescue) and $0.51 \times 10^{-5}$ colonies per cell on day 9 . The number of colonies in the P-depleted media kept increasing to $5.8 \times 10^{-5}$ colonies per cell by day 6 and on 
Table 2 Characteristics of trichome and colony morphologies for T. erythraeum IMS101 in YBCII replete, P-depleted, and Fe-depleted media

\begin{tabular}{lllr}
\hline & Trichome length $(\mathrm{mm})$ & Colony length $(\mathrm{mm})$ & Colony volume $\left(\mathrm{mm}^{3}\right)$ \\
\hline Replete media & $0.45 \pm 0.27$ & & \\
Fe-depleted media & $0.32 \pm 0.27$ & $0.52 \pm 0.27$ & $1.2 \times 10^{-3} \pm 2.0 \times 10^{-3}$ \\
P-depleted media & $0.50 \pm 0.26$ & $1.25 \pm 0.56$ & $5.8 \times 10^{-4} \pm 6.0 \times 10^{-4}$ \\
\hline
\end{tabular}

Averages of trichome length \pm SD on day 2 for Fe-depleted YBCII media, on day 6 for P-depleted YBCII media, and on day 0 for replete YBCII media $(n=150, p<0.01$ for Fe-depleted trichomes compared to P-depleted and replete media). Colony length and volume average \pm SD $(n=73$, $p<0.01$ for Fe-depleted colonies length compared to P-depleted, change in volume was not significant) on day 2 for Fe-depleted YBCII media and on day 6 for P-depleted YBCII media. $n=3$ per treatment

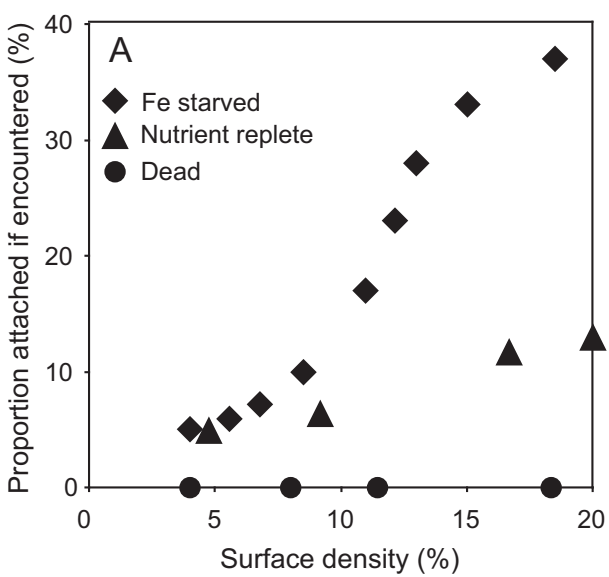

Fig. 6 The fraction (in $\%$ of cells) that remained attached for at least $30 \mathrm{~s}$ (a) and coalesced if attached (b) vs. the cellular concentration (surface density) of dead cultures (black circles), nutrient-replete cultures (black triangles), and Fe-depleted cultures (black diamonds) of $T$.

day 9 it was significantly higher, $8.7 \times 10^{-5}$ colonies per cell $(p<0.001, n=3)$ (Fig. 5h).

\section{Motility and aggregation of trichomes to colonies under nutrient depletion}

The mean square displacements shown in Fig. 3e were similar between treatments (see dashed gray lines) indicative of no significant differences in cellular motility patterns of individual trichomes between cultures that were grown under replete conditions or Fe-depleted conditions. To further test the differences between the two cases, we examined the probability of trichomes to (i) briefly attach (for at least $30 \mathrm{~s}$ ) if encountered (Fig. 6a), and to (ii) remain together (coalesce) if previously attached (Fig. 6b). This was done by examining the fraction of trichomes that satisfied these conditions out of the total number quantified in the field of view. In the Fe-replete cultures, the maximal probability of attachment between encountered trichomes reached only $12 \%$ at maximal surface density while the probability of trichomes to remain coalesced if attached only $10 \%$ (Fig. 6a, b). When Fe was depleted, and as the density of trichomes increased in the cultures, the probability of attachment between encountered trichomes rose to

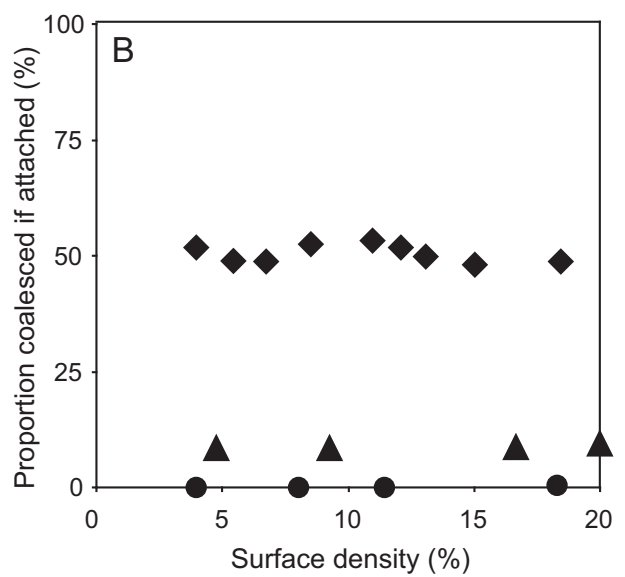

erythraeum IMS101. Probabilities were calculated from analyses of six videos each from Fe-depleted media (SV2) and Fe-replete media (SV3), and six videos of dead cultures - two videos each from the different killing methods

$>35 \%$ (Fig. 6a). Furthermore, the probability of coalescing if attached for Fe-depleted trichomes was independent of surface cell density and rose to $\sim 50 \%$ compared with only $10 \%$ of the nutrient-replete cultures that remained attached (Fig. 6b).

\section{Discussion}

\section{Induction, formation, and cohesiveness of colonies}

Trichodesmium employs various strategies to enhance the uptake and acquisition of $\mathrm{Fe}$ and $\mathrm{P}$ that are critical for its growth and productivity in the nutrient-limited surface oceans [13, 17-19, 32-34]. Our current results provide new evidence illustrating how stress, induced by $\mathrm{Fe}$ and $\mathrm{P}$ limitation, stimulates trichome aggregation and colony formation in Trichodesmium (Figs. 2, 4, 5, and 6). Our data clearly demonstrates that although all live trichomes have similar characteristic movements, whether under replete or limited $\mathrm{Fe}$ (Fig. 3e), nutrient deprivation enhances the probability for motile trichomes to connect, remain attached, and initiate colony formation (Figs. 3 and 6, Supplementary Figure S1). Finally, when Fe or P are re- 
introduced to nutrient-limited cultures, colony numbers decline and free trichomes predominate in the cultures (Fig. 5g, h).

The mechanism of motility (and colony attachment) in Trichodesmium is currently unknown and is not the objective of our study. Yet, our data also provide evidence supporting the coalescing of the trichomes (Fig. 6b) and the tight connective nature of the trichomes in the colonies formed under P and Fe depletion (Fig. 2 and Supplemental Figure S1). Nutrient stress in Trichodesmium stimulates the production of transparent extracellular polysaccharides (TEP) [29, 35]. Polysaccharide sheaths or mucus are commonly produced in colonial cyanobacteria such as the unicellular Microcystis or the filamentous Nostoc [36, 37]. In Trichodesmium, this sticky matrix can help consolidate colonial morphology and structure as illustrated from the higher adhesive forces between trichomes in colonies quantified by AFM (Supplementary Figure S1). The polysaccharide matrix also provides a carbon-rich substrate for the associated microbiome (reviewed in ref. [38]) to recycle and enhance nutrient concentrations near the colonies [19].

Although we do not know the structural composition of the connective cellular appendages between adjacent trichomes (Fig. 2), varied intercellular connective systems exist in Bacillus subtilis, Geobactor spp., and other bacterial species [39] (reviewed in ref. [40]). These connections occur both intra- and inter-specifically with nanowires or nanotubes bridging the cells [39], or with outer membrane extensions and vesicle chains as observed in Shewanella oneidensis [41]. Moreover, these lipid and carbohydratebased vesicle appendages proliferate in biofilms of $M y x$ ococcus xanthus [42], suggesting a possible role in colony formation. These connections provide both a physical glue and a conduit for transported molecules and communications from one cell to another [42]. We hypothesize this occurs similarly between trichomes within the Trichodesmium colony (Fig. 2a, b, c, d, e), possibly aided by associated epibionts found in oceanic populations [43], as well as in the non-axenic Trichodesmium IMS101 cultures (Supplementary Table S1).

Additionally, the hair-like structures we observed extruding from the trichomes (Fig. 2f) may be similar to pili-like structures as discovered in several cyanobacteria [44], including the filamentous Nostoc punctiforme that has two types of pili-like structures, short/thin pili-like structures as in other bacteria, and novel interconnecting long/ thick pili-like structures [45]. Both types of pili-like structures can act as microbial nanowires, however their function remains unknown [45]. No data is currently available regarding pili-like structures or function/s for Trichodesmium IMS101 although preliminary genomic searches revealed seven genes that may potentially be related to motility and pili formation (https://www.ncbi.nlm.nih.gov/ bioproject/?term $=$ PRJNA304389, sample accessions SAMN05207415, SAMN05207416, and SAMN05207417).

\section{Differential impacts of Fe and P stress on colony formation and morphology}

Decreased availability of Fe produced a much more rapid formation of colonies in Fe-depleted colonies compared to P-depleted colonies (24-48 h vs. 5-7 days, respectively) (Fig. 5). The shorter Fe-depleted trichomes (Table 2) conform with previous data demonstrating that $\mathrm{Fe}$ limitation generally causes a reduction in both trichome length and in growth rates [25, 46]. P-limitation (under ambient $\mathrm{CO}_{2}$ ) did not change the average trichome length compared to that measured in replete cultures [34] consistent with measurements of the P-depleted trichomes here (Table 2).

Fe limitation in Trichodesmium negatively impacts photosynthetic rates, synthesis of enzymes, and proteins such as nitrogenase and PSI, and subsequently growth [25]. Moreover, depletion of $\mathrm{Fe}$, as in our experiments, stimulates rapid biochemical and physiological responses such as upregulation of the iron stress gene $i s i B$ [29] and induces a programmed cell death pathway that can cause an exponentially growing biomass to crash 2-4 days after $\mathrm{Fe}$ is depleted from the media [23, 25, 35]. Thus, the formation of colonies 1 day after cultures were transferred to Fe-depleted media (Fig. 5), and the inability to revert back to single trichomes when $\mathrm{Fe}$ was added back to the medium 2 days after depletion (data not shown), further substantiate the acute nature of $\mathrm{Fe}$ depletion [47, 48] and the potential importance of the colonial morphology in alleviating this stress.

The advantages of the colonial morphology when $\mathrm{Fe}$ is limiting has been demonstrated from several oceanic and culture studies. Eolian dust transport provides a principal source of Fe to the open surface ocean [49]. However, this supply is typically episodic and stochastic [50]. Thus, Trichodesmium must efficiently take up $\mathrm{Fe}$ to meet its requirements [25, 47]. Dense surface blooms of Trichodesmium can enhance the capture rate of atmospheric dust particles as they sink through the water column [18]. Puffshaped colonies of Red-Sea populations of Trichodesmium spp. adsorb, actively shuttle, and package desert dust within their core, thus enhancing $\mathrm{Fe}$ and ferrihydrite dissolution and assimilation [17]. Fe-replete laboratory cultures consisting of free trichomes cannot adsorb dust and only enhance ferrihydrite dissolution [17]. Moreover, the natural puff populations are more effective at ferrihydrite dissolution when rates are normalized per trichome [17]. In other laboratory cultures of Trichodesmium, Fe uptake by single trichomes was largely from $\mathrm{FeCl}_{3}$ and weak organic ligands such as Fe-citrate and minimally from siderophore-bound $\mathrm{Fe}$ [51]. 
In contrast to the dramatic response to Fe limitation that began $24 \mathrm{~h}$ after depletion of $\mathrm{Fe}, \mathrm{P}$ limitation during the 9 days of the experiment resulted in slower rates of colony formation, fewer colonies, and minor changes in trichome morphology (Figs. 4 and 5 and Table 2). This more flexible response is consistent with Trichodesmium's diverse strategies in procuring and utilizing $\mathrm{P}$ [33, 52-55]. Trichodesmium can also use excess $\mathrm{P}$ when available (luxury uptake), store it in the form of polyphosphate [56, 57], and modify cellular $\mathrm{P}$ requirements via flexible elemental stoichiometry $[34,58]$. These adaptations provide a "buffer" to $\mathrm{P}$ depletion, so that growth can be sustained for longer upon $\mathrm{P}$ limitation as observed with only a slight reduction in growth rates compared to the P-replete cultures (Fig. 5).

Yet, our data clearly shows that $\mathrm{P}$ depletion induced colony formation (Fig. 5d) while $\mathrm{P}$ enrichment caused colonies to disassociate (Fig. 5h). Thus, colonial morphologies must provide an added benefit when $\mathrm{P}$ is limiting. Colony formation enlarges the effective cell size which, together with altered cellular buoyancy via carbohydrate ballasting and gas vesicles, enhances vertical migration to "mine" nutrients such as $\mathrm{P}$ below the nuticline [13-16, 59].

Colonies have an additional advantage in their role as microbial "hot spots", hosting a diverse microbiome [5, 6062]. Enzymatic activity and nutrient recycling by the associated epibionts can increase both $\mathrm{Fe}$ and $\mathrm{P}$ availability for Trichodesmium [19, 51, 61-63]. Moreover, co-evolution of specific epibionts such as Alteromonas macleodii with Trichodesmium colonies [64], similar to associated bacteria in the Trichodesmium IMS101 cultures (Supplementary Table S1), can provide functional solutions such as enhanced alkaline phosphatase activity to facilitate $\mathrm{P}$ acquisition under limited conditions [19] or detoxification of ROS within the consortia [64].

Trichodesmium is not unique in its colony-forming strategy. Colony formation has been linked to nutrient stress in other cyanobacteria and in eukaryotic phytoplankton. Declining availability of total $\mathrm{N}$ and $\mathrm{P}$ stimulated the formation of aggregates and induced the development of larger colonies in the unicellular colony forming fresh-water cyanobacteria Microcystis spp. [65]. Moreover, high concentrations of combined $\mathrm{N}$ and $\mathrm{P}$ caused colonial morphologies of Microcystis to disappear [65]. Other environmental drivers (e.g., temperature, salinity, pH, light, and UVR) [65-67] and biotic factors (e.g., grazing, allelopathy, and other interspecific interactions) [68-71] induce colony formation in cyanobacteria and other phytoplankton. Dominant factors such as nutrient deprivation may drive the formation of colonies. Yet, ultimately colony formation, morphology, and function are probably a response to an ensemble of several other stressors as demonstrated.

Furthermore, our data show conclusively that colonies in Trichodesmium can begin to form within several hours
( $\sim 6-10 \mathrm{~h}$ from depletion). Such a rapid reaction is probably much more prevalent in oceanic colonies that form from trichomes that are not necessarily genetically identical or from different Trichodesmium species [4, 5]. When a rapid response rate to changed environmental conditions is required, this ability to aggregate and form functional colonies is clearly advantageous, compared to colonies formed by cell division [72].

\section{Is colony formation related to Fe or $P$ availability in the ocean?}

If colonies are a response to nutrient limitation and specifically to $\mathrm{P}$ and Fe availability, we expect that the oceanic concentrations of these nutrients may impact the distribution and abundance of trichomes and colonies of oceanic Trichodesmium populations. We found no apparent trend when we reviewed the literature to compare the measured ambient dissolved inorganic P (DIP) concentrations and the reported distribution of free trichomes and colonies (Supplementary Table S3).

Several factors contribute to the lack of correspondence. Often, published counts are from experimental manipulations of colonies "picked" out of tows or from the Niskin bottles [26, 73, 74]. While, in situ imaging microscopes such as the video plankton recorder provide colony, but not free trichome, abundance [24, 75]. Thus, colony numbers are often reported [73, 76-78] while free trichomes are reported infrequently [1, 79]. Most importantly, routine counts of both colonies and free trichomes, reported with the corresponding ambient nutrient concentrations, are scarce [80] limiting our comparative analysis.

Furthermore, Trichodesmium's flexible $\mathrm{P}$ acquisition strategies would enhance survival and growth under low $\mathrm{P}$ for both free trichomes and colonies. Thus, in the oceans, we would not necessarily observe a direct correlation between ambient $\mathrm{PO}_{4}$ concentrations and colony formation as we consistently demonstrated in laboratory cultures (Fig. 5d, h).

The more acute response of Trichodesmium colony formation to Fe-stress could perhaps yield a better global comparison examining the coupling between ambient $\mathrm{Fe}$ concentrations and distribution of colonies vs. trichomes. However, we found only one study that examined colony and free trichome abundance in relationship to ambient $\mathrm{Fe}$ concentrations [80]. Thus, correlating between Fe availability and colony abundance from published oceanic studies is currently impossible and should be explored in the future.

\section{Conclusions}

Research on Trichodesmium has elucidated many strategies that have enabled its survival and predominance in the vast 
expanses of the oligotrophic subtropical and tropical oceans for well over 2 billion years. Our results also clearly demonstrate that different levels of either $\mathrm{P}$ and $\mathrm{Fe}$ stress induce trichome aggregation and promote cohesion leading to colonial morphologies in Trichodesmium. We hypothesize that nutrient deprivation drives the transition between trichomes and colonies in oceanic Trichodesmium with cellular motility enabling a rapid and flexible response between morphologies. Moreover, to enhance colonial formation and morphology, coordinated genetically regulated functions and a communication network must operate between the individual trichomes themselves and their associated holobiont populations. Signals and pathways such as quorum sensing molecules [19], nanotubes [39], and nanowires [45] mediate such interactions, and may be channeled through connective appendages such as we observed between trichomes (Fig. 2). These combined attributes facilitate the continued survival of Trichodesmium in the dynamic environment of the past, present, and future ocean.

Acknowledgements We thank Dr. Avi Jacob of the light microscopy unit and Dr. Yaakov Langsam of the E-SEM unit at Bar Ilan University for their generous help and support in preparation and analyses. $\mathrm{AB}$ is thankful for partial support from the Israel Science Foundation Grant No. 373/16, and the Roy J. Zuckerberg Career Development Chair for Water Research for partial support. Funding for IBF was via the Schulich Ocean Studies Centre Initiative at Dalhousie University, and a collaborative grant from MOST Israel and the High Council for Science and Technology (HCST), France. This work is in partial fulfillment of the requirements for a $\mathrm{PhD}$ thesis for $\mathrm{YT}$ and an MSc thesis for LM at Bar Ilan University. Support for YT was provided with a student fellowship from the Mediterranean Sea Research Center of Israel (MERCI).

\section{Compliance with ethical standards}

Conflict of interest The authors declare that they have no conflict of interest.

\section{References}

1. Carpenter EJ, Subramaniam A, Capone DG. Biomass and primary productivity of the cyanobacterium Trichodesmium spp. in the tropical N Atlantic ocean. Deep Sea Res I. 2004;51:173-203.

2. Capone DG, Zehr JP, Paerl HW, Bergman B, Carpenter EJ. Trichodesmium, a globally significant marine cyanobacterium. Science. 1997;276:1221-9.

3. Hynes AM, Webb EA, Doney SC, Waterbury JB. Comparison of cultured Trichodesmium (Cyanophyceae) with species characterized from the field. J Phycol. 2012;48:196-210.

4. Eichner MJ, Klawonn I, Wilson ST, Littmann S, Whitehouse MJ, Church MJ, et al. Chemical microenvironments and single-cell carbon and nitrogen uptake in field-collected colonies of Trichodesmium under different pCO2. ISME J. 2017; 11:1305-17.

5. Rouco M, Haley ST, Dyhrman ST. Microbial diversity within the Trichodesmium holobiont. Environ Microbiol. 2016;18:5151-60.

6. Moore CM, Mills MM, Arrigo KR, Berman-Frank I, Bopp L, Boyd PW, et al. Processes and patterns of oceanic nutrient limitation. Nat Geosci. 2013;6:701-10.
7. Dugdale RC, Menzel DW, Ryther J. Nitrogen fixation in the Sargasso Sea. Deep Res. 1961;7:297-300.

8. Carpenter E, Price C. Marine oscillatoria (Trichodesmium): explanation for aerobic nitrogen fixation without heterocysts. Science. 1976;191:1278-80.

9. Saino T, Hattori A. Aerobic nitrogen fixation by the marine nonheterocystous cyanobacterium Trichodesmium (Oscillatoria) spp.: Its protective mechanism against oxygen. Mar Biol. 1982;70:251-4.

10. Berman-Frank I, Lundgren P, Chen Y-B, Kupper H, Kolber Z, Bergman B, et al. Segregation of nitrogen fixation and oxygenic photosynthesis in the marine cyanobacterium Trichodesmium. Science. 2001;294:1534-7.

11. Paerl HW. Spatial segregation of $\mathrm{CO}_{2}$ fixation in Trichodesmium spp.: linkage to N2 fixation potential. J Phycol. 1994;30:790-9.

12. Robson BJ, Baird M, Wild-Allen K. A physiological model for the marine cyanobacteria, Trichodesmium. In: Piantadosi J, Anderssen R, Boland J, editors. MODSIM2013, 20th International Congress on Modelling and Simulation. Ade laide: Modelling and Simulation Society of Australia and New Zealand; 2013. p. 1652-8.

13. Villareal TA, Carpenter EJ. Buoyancy regulation and the potential for vertical migration in the oceanic cyanobacterium Trichodesmium. Microb Ecol. 2003;45:1-10.

14. White AE, Spitz YH, Letelier RM. Modeling carbohydrate ballasting by Trichodesmium spp. Mar Ecol Prog Ser. 2006;323:35-45.

15. Letelier RM, Karl DM. Trichodesmium spp. physiology and nutrient fluxes in the North Pacific subtropical gyre. Aquat Microb Ecol. 1998;15:265-76.

16. Walsby AE. The properties and buoyancy-providing role of gas vacuoles in Trichodesmium Ehrenberg. $\mathrm{Br}$ Phycol J. 1978;13:103-16.

17. Rubin M, Berman-Frank I, Shaked Y. Dust- and mineral-iron utilization by the marine dinitrogen-fixer Trichodesmium. Nat Geosci. 2011;4:529-34.

18. Rueter JG, Hutchins DA, Smith RW, Unsworth NL. Iron nutrition of Trichodesmium. In: Carpenter EJ, Capone DG, Rueter JG, editors. Marine pelagic cyanobacteria: Trichodesmium and other diazotrophs. Dordrecht: Springer Netherlands; 1992. p. 289-306.

19. Van-Mooy BAS, Hmelo LR, Sofen LE, Campagna SR, May AL, Dyhrman ST, et al. Quorum sensing control of phosphorus acquisition in Trichodesmium consortia. ISME J. 2011;6:422-9.

20. Chen Y-BB, Zehr JP, Mellon M. Growth and nitrogen fixation of the diazotrophic filamentous nonheterocystous cyanobacterium Trichodesmium sp IMS 101 in defined media: evidence for a circadian rhythm. J Phycol. 1996;32:916-23.

21. Bell PRF, Uwins PJR, Elmetri I, Phillips JA, Fu FX, Yago AJE. Laboratory culture studies of Trichodesmium isolated from the Great Barrier Reef lagoon, Australia. Hydrobiologia. 2005;532:9-21.

22. Ohki K, Fujita Y. Aerobic nitrogenase activity measured as acetylene reduction in the marine non-heterocystous cyanobacterium Trichodesmium spp. grown under artificial conditions. Mar Biol. 1988;98:111-4.

23. Berman-Frank I, Bidle KD, Haramaty L, Falkowski PG. The demise of the marine cyanobacterium, Trichodesmium., via an autocatalyzed cell death pathway. Limnol Oceanogr. 2004;49:997-1005.

24. Davis CS. Transatlantic abundance of the N2-fixing colonial cyanobacterium Trichodesmium. Science. 2006;312:1517-20.

25. Berman-Frank I, Cullen JT, Shaked Y, Sherrell RM, Falkowski PG. Iron availability, cellular iron quotas, and nitrogen fixation in Trichodesmium. Limnol Oceanogr. 2001;46:1249-60.

26. Sañudo-Wilhelmy SA, Kustka AB, Gobler CJ, Hutchins DA, Yang M, Lwiza K, et al. Phosphorus limitation of nitrogen 
fixation by Trichodesmium in the central Atlantic Ocean. Nature. 2001;411:66-69.

27. Snow JT, Schlosser C, Woodward EMS, Mills MM, Achterberg EP, Mahaffey C, et al. Environmental controls on the biogeography of diazotrophy and Trichodesmium in the Atlantic Ocean. Glob Biogeochem Cycles. 2015;29:865-84.

28. Chappell PD, Webb EA. A molecular assessment of the iron stress response in the two phylogenetic clades of Trichodesmium. Environ Microbiol. 2010;12:13-27.

29. Bar-Zeev E, Avishay I, Bidle KD, Berman-Frank I. Programmed cell death in the marine cyanobacterium Trichodesmium mediates carbon and nitrogen export. ISME J. 2013;7:2340-8.

30. Gamliel H, Gurfel D, Leizerowitz R, Polliack A. Air-drying of human leucocytes for scanning electron microscopy using the GTGO procedure. J Microsc. 1983;131:87-95.

31. Stihl A, Sommer U, Post AF. Alkaline phosphatase activities among populations of the colony-forming diazotrophic cyanobacterium Trichodesmium spp. (cyanobacteria) in the Red Sea. J Phycol. 2001;37:310-7.

32. Dyhrman ST, Chappell PD, Haley ST, Moffett JW, Orchard ED, Waterbury JB, et al. Phosphonate utilization by the globally important marine diazotroph Trichodesmium. Nature. 2006;439:68-71.

33. Polyviou D, Hitchcock A, Baylay AJ, Moore CM, Bibby TS. Phosphite utilization by the globally important marine diazotroph Trichodesmium. Environ Microbiol Rep. 2015;7:824-30.

34. Spungin D, Berman-Frank I, Levitan O. Trichodesmium's strategies to alleviate phosphorus limitation in the future acidified oceans. Environ Microbiol. 2014;16:1935-47.

35. Berman-Frank I, Rosenberg G, Levitan O, Haramaty L, Mari X. Coupling between autocatalytic cell death and transparent exopolymeric particle production in the marine cyanobacterium Trichodesmium. Environ Microbiol. 2007;9:1415-22.

36. Sand-Jensen K. Ecophysiology of gelatinous Nostoc colonies: unprecedented slow growth and survival in resource-poor and harsh environments. Ann Bot. 2014;114:17-33.

37. Zhang M, Shi X, Yu Y, Kong F. The acclimative changes in photochemistry after colony formation of the cyanobacteria Microcystis aeruginosa. J Phycol. 2011;47:524-32.

38. Sellner KG. Physiology, ecology, and toxic properties of marine cyanobacteria blooms. Limnol Oceanogr. 1997;42:1089-104.

39. Dubey GP, Ben-Yehuda S. Intercellular nanotubes mediate bacterial communication. Cell. 2011;144:590-600.

40. Sure S, Ackland ML, Torriero AAJ, Adholeya A, Kochar M. Microbial nanowires: an electrifying tale. Microbiology. 2016;162:2017-28.

41. Pirbadian S, Barchinger SE, Leung KM, Byun HS, Jangir Y, Bouhenni RA, et al. Shewanella oneidensis MR-1 nanowires are outer membrane and periplasmic extensions of the extracellular electron transport components. Proc Natl Acad Sci USA. 2014;111:12883-8

42. Remis JP, Wei D, Gorur A, Zemla M, Haraga J, Allen S, et al. Bacterial social networks: structure and composition of $M y x$ ococcus xanthus outer membrane vesicle chains. Environ Microbiol. 2014;16:598-610.

43. Sheridan CC. The microbial and metazoan community associated with colonies of Trichodesmium spp.: a quantitative survey. J Plankton Res. 2002;24:913-22.

44. Sure S, Torriero AAJ, Gaur A, Li LH, Chen Y, Tripathi C, et al. Inquisition of Microcystis aeruginosa and Synechocystis nanowires: characterization and modelling. Antonie Van Leeuwenhoek. 2015;108:1213-25.

45. Sure S, Torriero AAJ, Gaur A, Li LH, Chen Y, Tripathi C, et al. Identification and topographical characterisation of microbial nanowires in Nostoc punctiforme. Antonie Van Leeuwenhoek. 2016;109:475-80.
46. Kupper H, Setlik I, Seibert S, Prasil O, Setlikova E, Strittmatter $\mathrm{M}$, et al. Iron limitation in the marine cyanobacterium Trichodesmium reveals new insights into regulation of photosynthesis and nitrogen fixation. New Phytol. 2008;179:784-98.

47. Berman-Frank I, Quigg A, Finkel ZV, Irwin AJ, Haramaty L. Nitrogen-fixation strategies and Fe requirements in cyanobacteria. Limnol Oceanogr. 2007;52:2260-9.

48. Schoffman H, Lis H, Shaked Y, Keren N. Iron-nutrient interactions within phytoplankton. Front Plant Sci. 2016;7:1-12.

49. Jickells TD. Global iron connections between desert dust, ocean biogeochemistry, and climate. Science. 2005;308:67-71.

50. Guieu C, Aumont O, Paytan A, Bopp L, Law CS, Mahowald N, et al. The significance of the episodic nature of atmospheric deposition to low nutrient low chlorophyll regions. Glob Biogeochem Cycles. 2014;28:1179-98.

51. Roe KL, Barbeau K, Mann EL, Haygood MG. Acquisition of iron by Trichodesmium and associated bacteria in culture. Environ Microbiol. 2012;14:1681-95.

52. Dyhrman ST, Benitez-Nelson CR, Orchard ED, Haley ST, Pellechia PJ. A microbial source of phosphonates in oligotrophic marine systems. Nat Geosci. 2009;2:696-9.

53. Orchard ED, Webb EA, Dyhrman ST. Molecular analysis of the phosphorus starvation response in Trichodesmium spp. Environ Microbiol. 2009;11:2400-11.

54. Sohm J, Capone D. Phosphorus dynamics of the tropical and subtropical North Atlantic: Trichodesmium spp. versus bulk plankton. Mar Ecol Prog Ser. 2006;317:21-28.

55. White AE, Karl DM, Björkman KM, Beversdorf LJ, Letelier RM, White AE, et al. Phosphonate metabolism by Trichodesmium IMS101 and the production of greenhouse gases. Limnol Oceanogr. 2010;55:1768-78.

56. Orchard ED, Benitez-Nelson CR, Pellechia PJ, Lomas MW, Dyhrman ST. Polyphosphate in Trichodesmium from the lowphosphorus Sargasso Sea. Limnol Oceanogr. 2010;55:2161-9.

57. Romans KM, Carpenter EJ, Bergman B. Buoyancy regulation in the colonial diazotrophic cyanobacterium Trichodesmium tenue: ultrastructure and storage of carbohydrate, polyphosphate, and nitrogen. J Phycol. 1994;30:935-42.

58. White AE, Spitz YH, Karl DM, Letelier RM. Flexible elemental stoichiometry in Trichodesmium spp. and its ecological implications. Limnol Oceanogr. 2006;51:1777-90.

59. Beardall J, Allen D, Bragg J, Finkel ZV, Flynn KJ, Quigg A, et al. Allometry and stoichiometry of unicellular, colonial and multicellular phytoplankton. New Phytol. 2009;181:295-309.

60. Hewson I, Poretsky RS, Dyhrman ST, Zielinski B, White AE, Tripp HJ, et al. Microbial community gene expression within colonies of the diazotroph, Trichodesmium, from the Southwest Pacific Ocean. ISME J. 2009;3:1286-1300.

61. Hmelo L, Van Mooy B, Mincer T. Characterization of bacterial epibionts on the cyanobacterium Trichodesmium. Aquat Microb Ecol. 2012;67:1-14.

62. Momper LM, Reese BK, Carvalho G, Lee P, Webb EA. A novel cohabitation between two diazotrophic cyanobacteria in the oligotrophic ocean. ISME J. 2015;9:882-93.

63. Orchard ED, Ammerman JW, Lomas MW, Dyhrman ST. Dissolved inorganic and organic phosphorus uptake in Trichodesmium and the microbial community: The importance of phosphorus ester in the Sargasso Sea. Limnol Oceanogr. 2010;55:1390-9.

64. Lee MD, Walworth NG, McParland EL, Fu F-X, Mincer TJ, Levine NM, et al. The Trichodesmium consortium: conserved heterotrophic co-occurrence and genomic signatures of potential interactions. ISME J. 2017;11:1813-24.

65. Ma J, Brookes JD, Qin B, Paerl HW, Gao G, Wu P, et al. Environmental factors controlling colony formation in blooms of 
the cyanobacteria Microcystis spp. in Lake Taihu, China. Harmful Algae. 2014;31:136-42.

66. Callieri C, Lami A, Bertoni R. Microcolony formation by singlecell Synechococcus strains as a fast response to UV radiation. Appl Environ Microbiol. 2011;77:7533-40.

67. Yang H, Cai Y, Xia M, Wang X, Shi L, Li P, et al. Role of cell hydrophobicity on colony formation in Microcystis (cyanobacteria). Int Rev Hydrobiol. 2011;96:141-8.

68. Gan N, Xiao Y, Zhu L, Wu Z, Liu J, Hu C, et al. The role of microcystins in maintaining colonies of bloom-forming Microcystis spp. Environ Microbiol. 2012;14:730-42.

69. Van Donk E, Ianora A, Vos M. Induced defences in marine and freshwater phytoplankton: a review. Hydrobiologia. 2011;668:3-19.

70. Zhen Y, Kong F. Formation of large colonies: a defense mechanism of Microcystis aeruginosa under continuous grazing pressure by flagellate Ochromonas spp. J Limnol. 2012;71:61-66.

71. Callieri C, Amalfitano S, Corno G, Bertoni R. Grazing-induced Synechococcus microcolony formation: experimental insights from two freshwater phylotypes. FEMS Microbiol Ecol. 2016;92:1-10.

72. Oliver RL. Floating and sinking in gas-vacuolate cyanobacteria. J Phycol. 1994;30:161-73.

73. Holl CM, Villareal Ta, Payne CD, Clayton TD, Hart C, Montoya JP. Trichodesmium in the western Gulf of Mexico: 15N 2 -fixation and natural abundance stable isotopic evidence. Limnol Oceanogr. 2007;52:2249-59.

74. Villareal TA. Abundance and photosynthetic characteristics of Trichodesmium spp. along the Atlantic Barrier Reef at Carrie Bow Cay, Belize. Mar Ecol. 1995;16:259-71.

75. Olson EM, McGillicuddy DJ, Flierl GR, Davis CS, Dyhrman ST, Waterbury JB. Mesoscale eddies and Trichodesmium spp. distributions in the southwestern North Atlantic. J Geophys Res Ocean. 2015;120:4129-50.

76. Carpenter EJ, Romans KM. Major role of the cyanobacterium Trichodesmium in nutrient cycling in the North Atlantic. Ocean Sci. 1991;254:1356-8.

77. Mulholland MR, Floge S, Carpenter EJ, Capone DG. Phosphorus dynamics in cultures and natural population of Trichodesmim spp. Mar Ecol Prog Ser. 2002;239:45-55.

78. Orcutt KM, Gundersen K, Ammerman JW. Intense ectoenzyme activities associated with Trichodesmium colonies in the Sargasso Sea. Mar Ecol Prog Ser. 2013;478:101-13.

79. Letelier RM, Karl DM. Role of Trichodesmium spp. in the productivity of the subtropical North Pacific Ocean. Mar Ecol Prog Ser. 1996;133:263-73.

80. Rodier M, Le Borgne R. Population dynamics and environmental conditions affecting Trichodesmium spp. (filamentous cyanobacteria) blooms in the south-west lagoon of New Caledonia. J Exp Mar Bio Ecol. 2008;358:20-32. 